Journal of

\title{
Recognizing the Limitations and Pitfalls of Cytology for Anaplastic Carci- noma within Hürthle Cell (Oncocytic) Carcinomas
}

\author{
Timothy E. Richardson, DO, PhD, Shirley Yan, MD and Elizabeth M. Kurian, MD* \\ Department of Pathology, University of Texas Southwestern Medical Center, Dallas, TX 75390
}

${ }^{*}$ Corresponding author: Elizabeth M. Kurian, MD, Department of Pathology, University of Texas Southwestern Medical Center, Dallas, TX 75390; Email: Elizabeth.Kurian2@UTSouthwestern.edu

Received Date: April 13, 2015; Accepted Date: May 04, 2015; Published Date: May 07, 2015

Citation: Timothy E. Richardson, DO, PhD, et al. (2015) Recognizing the Limitations and Pitfalls of Cytology for Anaplastic Carcinoma within Hürthle Cell (Oncocytic) Carcinomas . J Clin Anat Pathol 2: 1-5.

\begin{abstract}
Fine needle aspiration is an initial method for diagnosis of enlarged thyroid nodules. Hürthle cell neoplasm is usually cytomorphologically distinct from undifferentiated/anaplastic thyroid carcinoma, except when there is marked atypia. Herein we contrast two cases, highlighting Hürthle cell atypia mimicking anaplastic change versus true anaplastic thyroid carcinoma. The first case is of a 44 year old female with a rapidly enlarging thyroid mass presenting with an outside fine needle aspiration diagnosis of anaplastic thyroid carcinoma; however the thyroidectomy found only a Hürthle cell follicular carcinoma with a component of cytologic atypia. The second case is from an 81 year old female with acute onset neck swelling. The cytologic evaluation was suspicious for a Hürthle cell neoplasm only, while the thyroidectomy showed Hürthle cell follicular carcinoma with anaplastic thyroid carcinoma. Hürthle cell neoplasm may have marked atypia, for which anaplastic thyroid carcinoma is important to exclude. Since fine needle aspirations have sampling limitations, subsequent surgical excision is essential in determining the correct diagnosis in cases of cytologic Hürthle cell neoplasm which may harbor anaplastic thyroid carcinoma.
\end{abstract}

Keywords: Cytology; FNA; Anaplastic thyroid carcinoma; Oncocytic carcinoma; Hürthle cell carcinoma

\section{Introduction}

Comprising roughly $4 \%$ of all thyroid cancers, Hürthle cell follicular carcinoma (HCFC) is a well-differentiated malignant tumor of the thyroid gland composed of mitochondrialrich oncocytes. Although most authors continue to consider it a variant of follicular cell carcinoma, HCFC has somewhat more aggressive behavior with an increased incidence of invasion and a higher predilection for lymphatic invasion [1]. Cytologic evaluation shows an abundance of oncocytic cells characterized by abundant polygonal cytoplasm, distinct cell borders, large nucleoli and large nuclei with occasional pleomorphism and atypia [1]. Hürthle cell neoplasms are typically well-encapsulated and considered malignant only when capsular invasion or lymphovascular invasion is noted [2]. While still showing some level of positivity in many cases, there appears to be decreased levels of TTF-1, TG and BCL2 in Hürthle cell adenomas and carcinomas compared with the surrounding thyroid tissue [3] and low levels of cyclin D1 positivity [4].

Unlike HCFC, the diagnosis of undifferentiated or anaplastic

(c)2015 The Authors. Published by the JScholar under the terms of the Creative Commons Attribution License http://creativecommons.org/licenses/ by $/ 3.0 /$, which permits unrestricted use, provided the original author and source are credited. thyroid carcinoma (ATC) is based on cytologic features with necrosis rather than evaluation of a capsule. ATC is one of the most aggressive and swiftly fatal tumors. Accounting for $5 \%$ of thyroid cancers, it typically arises from a background of well-differentiated thyroid carcinomas $[5,6]$ and has been documented to rarely arise from a Hürthle cell neoplasm $[7,8]$. Hunt et al. describes a high rate of allelic loss in Hürthle cell carcinomas, which would require less additional mutations to transform to ATC when compared to papillary thyroid carcinomas [9]. The clinical presentation of ATC is typically a rapidly enlarging tumor with invasion into surrounding thyroid tissue and adjacent neck structures. Histologically, it is very pleomorphic with striking atypia, multinucleated giant cells, spindled or squamoid cells, mitotic figures and necrosis [10]. ATC has a very high proliferative rate, in some studies surpassing $30 \%$ by MIB-1 staining, as well as an increased level of p53 staining as compared to well-differentiated thyroid tumors. In addition, these anaplastic neoplasms are often TTF- 1 and thyroglobulin (TG) negative $[11,12]$ and cyclin D1 positive [13] which could possibly aid in distinguishing them from follicular carcinoma variants.

We discuss the role of FNA in the diagnostic process of thyroid lesions alongside clinical, radiographic and histological findings; as well as the potential pitfalls of this modality in the context of these two case reports. 


\section{Case Report}

\section{Case 1}

The patient, a 44 year old female, noticed a painless rapidly enlarging right neck mass that had been present for the past 1.5 months. She stated that there was a feeling of pressure on her throat and with swallowing, but no stridor or difficulty breathing. On physical exam, there was a single right thyroid mass measuring approximately $6.0 \mathrm{~cm}$; without any palpable lymphadenopathy.

A neck CT scan at an outside institution indicated a $5.0 \times 4.0$ $\mathrm{cm}$ complex solid mass in the right thyroid producing tracheal deviation, which appeared encapsulated and contained within the thyroid. A follow-up PET scan showed an intense hypermetabolic mass in the right thyroid deemed consistent with malignancy; although no invasion or metastasis was seen. Neither of these radiographic studies showed evidence of lymph node involvement.

Within days of the initial CT scan, an ultrasound-guided fine needle aspiration (FNA) was performed at an outside hospital. FNA smears from this study demonstrated a significantly pleomorphic population of cells with marked nuclear atypia including prominent hyperchromatic macronucleoli and finely vacuolated to squamoid cytoplasm. The cells were arranged as dispersed isolated cells, as well as small cohesive cell clusters with occasional multinucleated giant cells within a background devoid of colloid or necrosis (Figs. 1A-B). The case was signed out as an undifferentiated (anaplastic) thyroid carcinoma.

Based on these preliminary findings the patient was scheduled for a total thyroidectomy with possible tracheal resection, as well as post-thyroidectomy thyroid ablation with Iodine-131 and Synthroid hormonal replacement. During surgery it was found that the mass did not extend outside of the right thyroid lobe and was not adherent to the trachea or esophagus. Intraoperatively, the surgeon noted the thyroid was soft, with the semblance of a multinodular goiter. Both thyroid lobes, as well as the isthmus were successfully dissected from the surrounding structures and sent for pathologic evaluation. Bilateral recurrent laryngeal nerves and the inferior left parathyroid were identified and unaffected by tumor.

On gross examination, multiple adhesions were noted along the capsule with the right thyroid lobe contained a single, tan multinodular mass measuring $5.2 \mathrm{~cm} \times 4.3 \mathrm{~cm} \times 3.5 \mathrm{~cm}$; which was submitted in its entirety. This Hürthle cell neoplasm was microscopically circumscribed and encapsulated with pushing invasion. There was likely vascular invasion on CD31 immunohistochemical staining (not shown); although this could not be unequivocally demonstrated. Histologically, the tumor was composed of trabeculae and small follicles of polygonal oncocytes (Figure 1C) with some areas containing large, atypical pleomorphic nuclei, prominent nucleoli and multinucleation (Figure 1D) without necrosis. On immunostaining, the clonal areas of pleomorphic cells were TTF-1 negative (Figure 3A), BCL-2 negative (Figure 3B), and cyclin D1 negative (Figure $3 \mathrm{C}$ ) in comparison to the background HCFC; which stained positive for all three stains. The HCFC had p53 positivity and

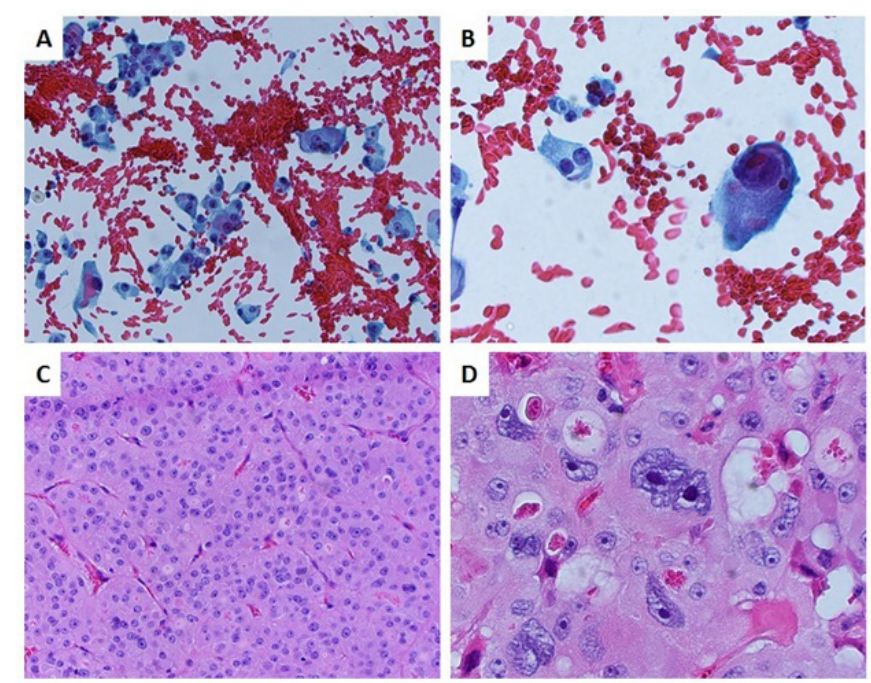

Figure 1: (A) Single cells, cell clusters and multinucleated giant cells exhibiting marked pleomorphism and anisonucleosis in a background of red blood cells (Papanicolaou stain, original magnification x200). (B) Single bizarre large cells present in a background of red blood cells (Papanicolaou stain, original magnification $\mathrm{x} 400$ ). (C) Small follicles of oncocytic cells that make up the bulk of the tumor (H\&E stain, original magnification x200). (D) Small areas of oncocytic cells showing marked pleomorphism and nuclear atypia ( $\mathrm{H} \& \mathrm{E}$, original magnification $\mathrm{x} 400$ ).

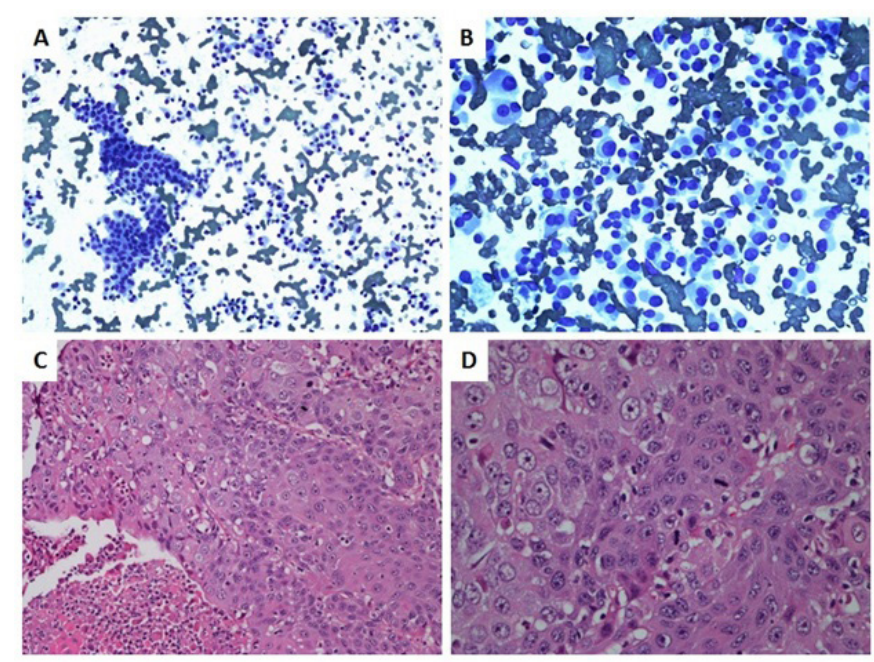

Figure 2: (A) Sheets and single cells of an apparent Hürthle cell neoplasm in a background of red blood cells (Diff Quick stain, original magnification x100). (B) Single cells of an apparent Hürthle cell neoplasm in a background of red blood cells (Diff Quick stain, original magnification x200). (C) Anaplastic thyroid carcinoma with extensive necrosis, squamoid changes, and mitotic figures (H\&E stain, original magnification x200) (D). Bizarre appearing cells with prominent enlarged nuclei, irregular nucleoli and multiple mitotic figures (H\&E stain, original magnification $\mathrm{x} 400)$.

a $5-10 \%$ proliferative rate as demonstrated by MIB-1 staining (not shown). This specimen was sent to The University of Pennsylvania for consultation, confirming the diagnosis of an oncocytic (Hürthle) follicular carcinoma with high levels of nuclear pleomorphism and likely lymphovascular infiltration. The final pathologic stage was pT3N0Mx.

\section{Case 2}

An 81 year old female who has subclinical hypothyroidism presented with acute onset neck swelling thought to be a leftsided goiter. Ultrasound-imaging showed a $3.5 \mathrm{~cm}$ nodule, which was aspirated. The cytologic specimen showed numerous follicular cells, both scattered singly and in sheet-like clus- 


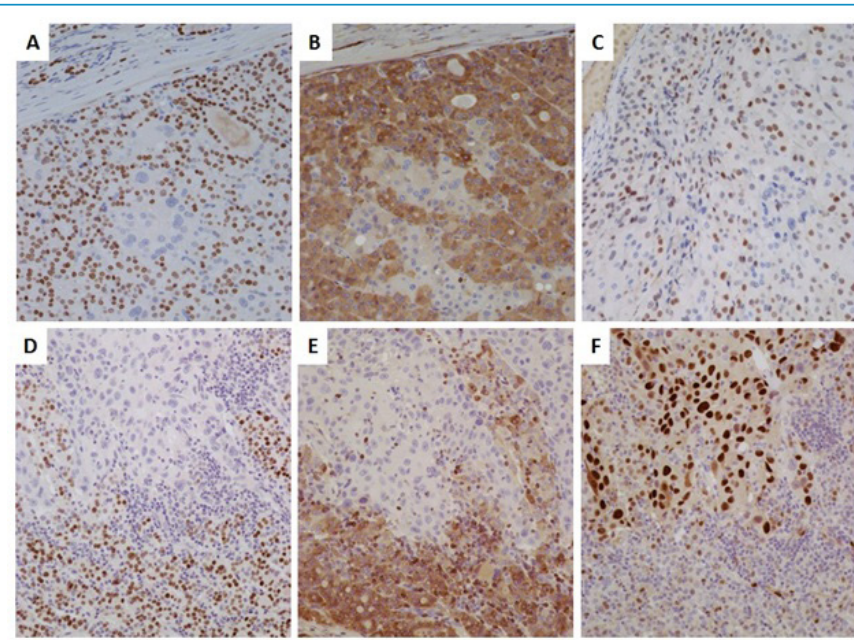

Figure 3: (A, Case 1) Clone of atypical cells negative for TTF-1 immunohistochemical staining; while background HCFC is positive (original magnification $\mathrm{x} 200)$. (B, Case 1) Clone of atypical cells is BCL-2 negative; background HCC is positive (original magnification x200). (C, Case 1) Clone of atypical cells cyclin D1 is negative; with a background of positively staining HCFC (original magnification $\mathrm{x} 200$ ). (D, Case 2 ) The squamoid anaplastic cells are negative for TTF-1 staining; as compared with the background HCC (original magnification $\mathrm{x} 200$ ). (E, Case 2) The squamoid anaplastic cells are negative for BCL-2 staining, in comparison to the background HCC (original magnification x200). (F, Case 2) Cyclin D1 staining shows positive staining in the squamoid anaplastic cells; while negative in the Hürthle cells (original magnification $\mathrm{x} 200$ ).

ters. The cells had round nuclei, prominent single nucleoli and granular basophilic cytoplasm (Figures 2A,2B). No features of papillary thyroid carcinoma were noted; however a Hürthle cell neoplasm was suspected.

The patient elected for a total thyroidectomy. During the surgery, a left paratracheal lymph node was diagnosed as positive for poorly differentiated/undifferentiated carcinoma with extranodal extension on frozen section. The resected thyroidectomy specimen showed a single circumscribed mass $(3.5 \times 3.0$ $\mathrm{x} 2.7 \mathrm{~cm}$ ) within the left lobe. The cut surface of the tumor was gray-white with central necrosis and a cystic area measuring $2.0 \mathrm{~cm}$ in greatest dimension.

Microscopically, the left thyroid displayed an encapsulated, oncocytic follicular mass with a rim of intact follicles and patchy areas of less differentiated carcinoma. The anaplastic component showed a spectrum of squamoid cells (Figures 2C,2D), clear cells to bizarre, pleomorphic spindled cells (not shown) with associated marked central tumor necrosis and fibrosis. Since the mass was composed of predominantly oncocytic follicular cells with mild cytologic atypia and focal capsular invasion, the diagnosis was oncocytic follicular carcinoma (Figure 2C). The high-grade malignant component also has focal capsular invasion with new tumor nodule formation composed of squamoid and spindle cells with frequent mitotic figures; which was consistent with undifferentiated (anaplastic) carcinoma arising from the HCFC (Figure 2D). The undifferentiated component was negative for TTF-1 (Figure 3D) and BCL-2 (Figure 3E) and cyclin D1 positive (Figure 3F) by immunohistochemistry, consistent with previous reports of ATC [12]. Eighteen level VI lymph nodes were examined, with only one positive for metastasis. The overall pathologic staging was pT4aN1aMx.

Four months later, the patient developed multiple lung nod- ules. The largest, $1.7 \mathrm{~cm}$ pulmonary nodule was aspirated and compatible with metastatic anaplastic thyroid carcinoma. The patient had chemoradiation therapy and is alive nine months after her thyroidectomy with tumor metastasis to her lung, liver and bone.

\section{Discussion}

In the first case, the clinical presentation of the tumor appeared very aggressive. According to the subjective history provided by the patient indicating that the mass had grown to over $5.0 \mathrm{~cm}$ in greatest dimension in a period of fewer than two months, and radiologic evaluation demonstrated that the tumor was impinging on both the esophagus and larynx. Cytological studies showed an aggressive appearing tumor (Figures $1 \mathrm{~A}, 1 \mathrm{~B}$ ) that was deemed by multiple pathologists to be consistent with anaplastic thyroid carcinoma. Final histology, also reviewed by multiple pathologists with expert consultation, showed a much less aggressive appearing tumor consistent with a Hürthle cell carcinoma with multiple cytologically atypical areas. Retrospectively, while the clinical manifestation correlated with the ultimate and erroneous diagnosis. It is the lack of a necrotic background that should have been a sentinel indicator to refrain from a definitive diagnosis of undifferentiated/anaplastic thyroid carcinoma. Interestingly, the resected thyroidectomy shows these atypical cells staining similar to an anaplastic thyroid carcinoma. This case with the atypical foci may represent an early clonal precursor to ATC.

In contrast, the second case demonstrates a relatively benign clinical presentation for which the cytological sampling found only the Hürthle cell component (Figures 2A,2B). These cases show the diagnostic challenges of correlating clinical-imaging findings and the challenges of sampling adequacy in determining management of thyroid nodules.

Anaplastic thyroid cancer is usually a straightforward diagnosis on FNA, as it shows frankly malignant features, including necrosis, striking nuclear pleomorphism/ atypia, pleomorphic multinucleated giant cells, very large cells and frequent single non-cohesive cells; cumulative features that are uncommon of more differentiated thyroid tumors [14]. The distinction between ATC and well-differentiated tumors, such as HCFC, can occasionally be difficult. ATC and poorly differentiated thyroid carcinoma can have a similar oncocytic appearance at first glance; and therefore may be mistaken for follicular cell thyroid carcinoma variants [15]. This distinction may be more challenging, since ATC can arise from Hürthle cell neoplasms $[7,8]$. In addition, Hürthle cell neoplasms can display a high level of nuclear pleomorphism and atypia (Figures 1B,1D) and high N/C ratio without being considered malignant [16]. Recent studies however, have shown that $83.5 \%$ of Hürthle cell neoplasms are placed in the correct category based solely on FNA [17].

Immunohistochemical staining can be helpful in differentiating ATC from Hürthle cell neoplasms in these questionable cases. Hürthle cell tumors are often positive for TTF-1 and BCL-2 while these markers are typically negative in ATC $[5,6]$. This is demonstrated in the background positive staining of the oncocytic cells in both cases, with negative staining in the atypical cells (Figures 3A,3B) and ATC (Figure 3D,3E). Hoos 
et al. describes down-regulation of BCL-2 expression associated with widely invasive Hürthle cell carcinomas; whereas BCL-2 expression in Hürthle cell carcinomas is associated with relapse-free and disease-specific survival [18].

An additional marker that could provide a distinction between the two tumors is cyclin D1 $[4,13]$. Authors have shown that a very low percentage of Hürthle cell neoplasms stain positive for cyclin D1 (1.7\% and 18\% in Hürthle cell adenomas and carcinomas, respectively), whereas the majority of ATC cases are positive for this marker (77\%). In our Case 1, cyclin D1 was negative in the atypical cells and positive in the background oncocytic carcinoma (Figure 3C). A reversed pattern was noted in case 2 , since the positive staining is limited to the anaplastic cells and only scattered cells within the background HCFC (Figure 3F).

Unfortunately, in the first case, stains could not be applied to the cell block produced at an outside hospital, as it did not contain tumor cells (not shown). The lack of tumor cells in the cell block, a fairly common occurrence with FNA sampling, prevented the application of immunostains for differentiation between an anaplastic thyroid tumor in favor of a follicular neoplasm. Given the somewhat variable expression levels of cyclin D1 in both Hürthle cell neoplasms and ATC $[4,13]$, it would be unwise to base an FNA diagnosis of malignancy on this marker alone. However, in combination with morphology and other markers as well as the proliferative index, cyclin D1 could prove to be a valuable tool in favoring a benign versus malignant process in cases that are difficult to classify based on FNA alone [11,12].

Fine needle aspiration is the most common first step in diagnosing a thyroid tumor, in order to determine next clinical step. For follicular cell neoplasms in particular, cytology cannot distinguish between benign and malignant, as this requires demonstration of capsular or vascular invasion [16]. In our first case, the combination of rapidly progressing clinical symptoms and marked cellular atypia suggested poorly differentiated/undifferentiated tumor but was actually a HCFC with atypia. Whereas, the second case shows a non-aggressive clinical presentation and bland oncocytic cytologic aspiration, that missed the significant underlying anaplastic carcinoma arising within HCFC. In these cases, we highlight the sampling limitations of FNA and susceptibility of clinical bias in formulating an accurate diagnosis. These cases reiterate the need to excise "gray-zone" lesions (i.e. HCFC and follicular neoplasms) for full pathologic evaluation, since ATC commonly develops from within well-differentiated carcinomas. Overall, in the setting of thyroid cytology, it is essential not only to correlate cytologic findings with clinical-radiographic findings; but to also recognize the limitations; which may require further excisional evaluation to obtain an accurate final diagnosis and treatment plan.

\section{Declaration of Interest}

The authors declare no conflict of interest.

\section{References}

1) Carcangiu ML, Bianchi S, Savino D, Voynick IM, Rosai J (1991) Follicular Hürthle cell tumors of the thyroid gland. Cancer 68: 19441953.
2) McLeod MK, Thompson NW (1990) Hürthle cell neoplasms of the thyroid. Otolaryngol Clin North Am 23:441-452.

3) Kanthan R, Radhi JM (1998) Immunohistochemical analysis of thyroid adenomas with Hürthle cells. Pathology 30:4-6.

4) Erickson LA, Jin L, Goellner JR, Lohese C, Pankratz VS, et al. (2000) Pathologic features, proliferative activity, and cyclin D1 expression in Hurthle cell neoplasms of the thyroid. Mod Pathol 13:186-192.

5) CarcangiuML, Steeper T, Zampi G, Rosai J (1985) Anaplastic thyroid carcinoma: a study of 70 cases. Am J Clin Pathol 83:135-158.

6) Kapp D, LiVolsi V, Sanders M (1982) Anaplastic carcinoma following well differentiated thyroid cancer: etiologic considerations. Yale J Biol Med 55:521-528.

7) Mai DD, Mai KT, Shamji FM (2001) Fine needle aspiration biopsy of anaplastic thyroid carcinoma developing from a Hürthle cell tumor: a case report. Acta Cytol 45:761-764.

8) Stucchi CM, Vaccaro V, Magherini A, Di Gregorio C, Greco G, et al. (2007) Hürthle cell follicular carcinoma of the thyroid gland presenting with diffuse meningeal carcinomatosis and evolving to anaplastic carcinoma. J Clin Pathol 60:831-832.

9) Hunt JL, Tometsko M,LiVolsi VA, Swalsky P, Finkelstein SD, et al. (2003) Molecular evidence of anaplastic transformation in coexisting well-differentiated and anaplastic carcinomas of the thyroid. Am J Surg Pathol 27:1559-1564.

10) Venkatesh YS, Ordonez NG, Schultz PN, Hickey RC, Goepfert H, et al. (1990) Anaplastic carcinoma of the thyroid. A Clinicopathologic study of 121 cases. Cancer 66:321-330.

11) Aratake $Y$, Nomura H, Kotani $T$, Marutsuka K, Kobayashi K, et al. (2006) Coexistant anaplastic and differentiated thyroid carcinoma: an immunohistochemical study. Am J Clin Pathol 125:399-406.

12) Wiseman SM, Masoudi H, Niblock P, Turbin D, Rajput A, et al. (2007) Anaplastic thyroid carcinoma: expression profile of targets for therapy offers new insights for disease treatment. Ann Surg Oncol14:719-729.

13) Wiseman SM, Griffith OL, Deen S, Rajput A, Masoudi H, et al. (2007) Identification of molecular markers altered during transformation of differentiated into anaplastic thyroid carcinoma. Arch Surg 142:717-727.

14) Baloch ZW, LiVolsi VA (2008) Fine-needle aspiration of the thyroid: today and tomorrow. Best Pract Res Clin Endocrinol Metab 22:929-939.

15) Rosai J, Carcangiu ML, DeLellis RA, Simoes MS (2000) Recommendations for the reporting of thyroid carcinomas. Association of directors of anatomic and surgical pathology. Hum Pathol 31:11991201.

16) Elliott DD, Pitman MB, Bloom L, Faquin WC (2005) Fine-needle aspiration biopsy of Hürthle cell lesions of the thyroid gland: a cytomorphologic study of 139 cases with statistical analysis. Cancer 108:102-109.

17) Eilers SG, LaPolice P, Mukunyadzi P, Kapur U, WendelSpiczka A, et al. (2014) Thyroid fine-needle aspiration cytology: performance data of neoplastic and malignant cases as identified from 1558 responses in the ASCP non-GYN assessment program thyroid fineneedle performance data. Cancer Cytopathol 112:745-750.

18) Hoos A, Stojadinovic A, Singh B, Dudas ME, Leung DHY, et al. (2002) Clinical significance of molecular expression profiles of Hürthle cell tumors of the thyroid gland analyzed via tissue microarrays. Am J Pathol 160:175-183. 
Submit your manuscript to a JScholar journal and benefit from:

q Convenient online submission

๑ Rigorous peer review

- Immediate publication on acceptance

- Open access: articles freely available online

9. High visibility within the field

- Better discount for your subsequent articles

Submit your manuscript at http://www.jscholaronline.org/submit-manuscript.php 